\title{
Chemical Inventory in the Eurasian Economic Union
}

\author{
Dieter Drohmann and Dominik Kirf*
}

\section{Introduction}

Ensuring chemical safety is considered as a priority issue in the Russian Federation and of strategic importance, as defined in 'The foundations of the state policy for ensuring chemical and biological safety of the Russian Federation for the period up to 2010 and longer terms', approved by the President of the Russian Federation, Vladimir Putin, on 4 December 2003. No Pr-2194. The policy is based on improving and strengthening of the relevant institutions and the legal framework. The aim is to create a comprehensive system providing for classification, volume forecasting, prevention, and elimination of chemical and biological threats, as well as the management of emergencies resulting from chemical and biological factors.

The Eurasian Economic Union (EAEU) ${ }^{1}$ is an economic union of states located in central and northern Asia and Eastern Europe. The Treaty on the Eurasian Economic Union was signed on 29 May 2014 by the leaders of Belarus, Kazakhstan and Russia, and came into force on 1 January 2015. Treaties aiming for Armenia's and Kyrgyzstan's accession to the Eurasian Economic Union were signed on 9 October and 23 December 2014, respectively. Armenia's accession treaty came into force on 2 January 2015. Kyrgyzstan's accession treaty came into effect on 6 August 2015. It participated in the EAEU from the day of its establishment as an acceding state.

The Eurasian Economic Union has an integrated single market of 180 million people and a gross do-

DOI: $10.21552 / \mathrm{icrl} / 2020 / 1 / 8$

* Dieter Drohmann is CEO of the Chemservice Group $<\mathrm{d}$ .drohmann@chemservice-group.com>. Dominik Kirf is Managing Director of Chemservice S.A. in Luxembourg $<d$ .kirf@chemservice-group.com>

1 See, <http://www.eaeunion.org/?lang=en> accessed 15 May 2020

2 Registration, Evaluation, Authorisation and Restriction of Chemicals - Regulation (EC) No 1907/2006

3 See, <http://www.rpohv.ru/lang/en/> accessed 15 May 2020.

4 See, <https://www.rospotrebnadzor.ru/en/> accessed 15 May 2020. mestic product of over \$5 trillion US\$. The EAEU encourages the free movement of goods and services and provides for common policies in the macroeconomic sphere, transport, industry and agriculture, energy, foreign trade and investment, customs, technical regulation, competition and antitrust regulation. Provisions for a single currency and greater integration are envisioned in future. The EAEU operates through supranational and intergovernmental institutions. The Supreme Eurasian Economic Council is the supreme body of the Union, consisting of the Heads of the Member States.

\section{Former Legislation and new Developments}

The Russian Federation implemented a registration system in 1992 which was amended several times to improve its effectiveness. Several Russian Federation Laws and Government Decrees deal with the safe use of chemicals and hazard communication. In the Russian Federation a mandatory state registration of potentially hazardous chemical and biological substances had been implemented in order to prevent adverse effects on human health and the environment. This was applicable to all chemical substances on their own or in mixtures as well as to biological compounds produced or imported into Russia. Production, import and use of unregistered substances was prohibited. From the start of the registration process until end of 2019, about 3.400 substances were registered. In the period before 1992, about 15.000 substances were evaluated under the former chemical regulation of the Soviet Union. These substances were considered as registered, too. Thus, the split into 'old' and 'new' substances was comparable with the pre-REACH ${ }^{2}$ chemicals legislation in the EU.

In most cases the registrations were performed by $\mathrm{FBEPH}^{3}$, the Russian Register of Potentially Hazardous Chemical and Biological Substances (RRPHCBS). FBEPH was a federal body empowered by Rospotrebnadzor ${ }^{4}$ - a 'Federal Service for 


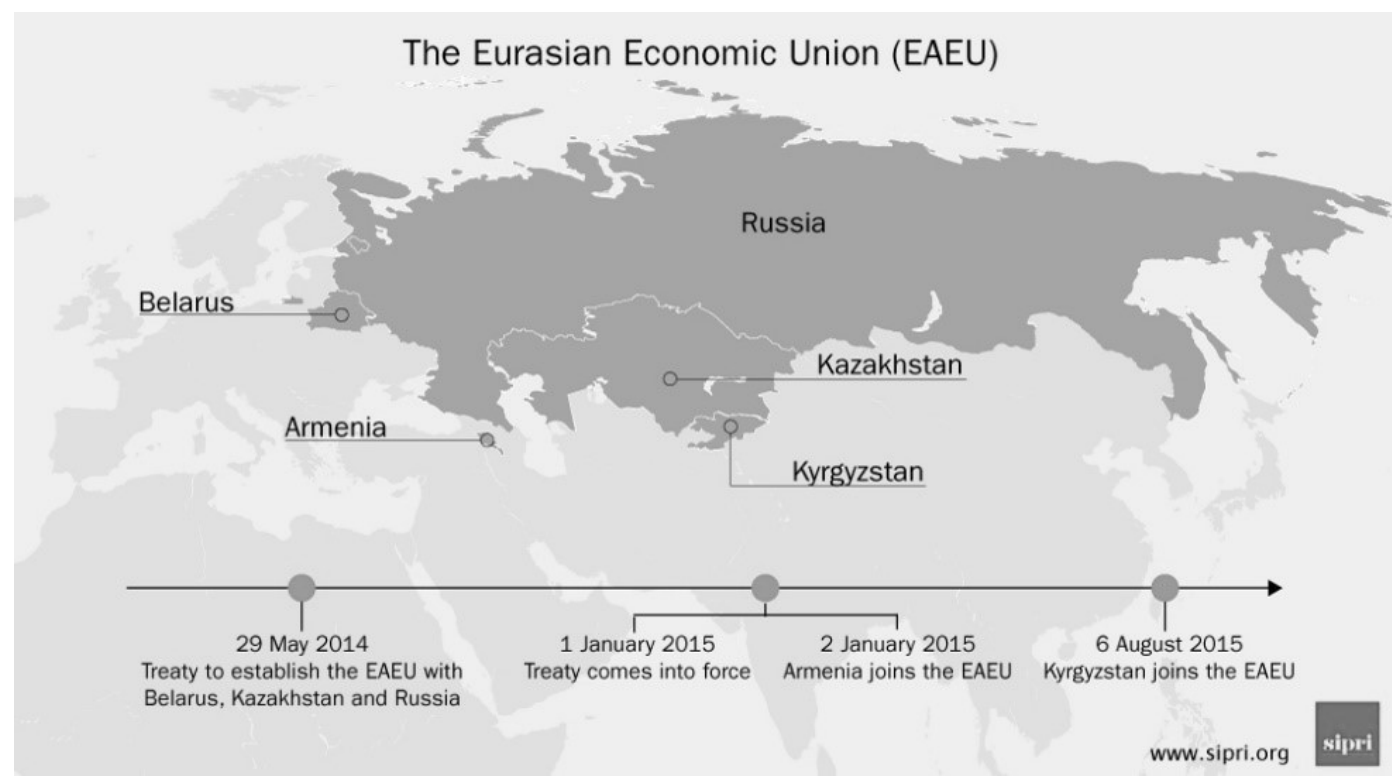

Figure 1: Geographical Location of the Eurasian Economic Union (Source: SIPRI)

Surveillance on Consumer Rights Protection and Human Well-being'. FBEPH issued a database for 'hazardous substances', which contained information about chemical compounds that passed state registration. There were more than 10.000 chemicals listed. It included data on physical and chemical properties; toxicity and hazard to humans and the environment; hygienic and environmental standards. The register involved sub-registers such as:

- Register of certificates on state registration;

- Register of products that have undergone state registration before 1 July 2010;

- Register of sanitary-epidemiological conclusions and others

On 7 October 2016 Russia approved a new chemical law, namely the technical regulation on the safety of chemical products, which will enter into force end of 2021 or early 2022. Comparable to REACH, the responsibilities for the evaluation of intrinsic properties, hazard, risk and exposure assessment as well as the creation of safety data sheets are shifted to industry - the manufacturer and importer. While existing substances (meaning those already listed to the inventory) only need to be notified, new substances or chemical products have to be registered as soon as they exceed the threshold of $0.1 \%$ in a formulation. This registration is mandatory, irrespective of any tonnage bands. Information requirements for the registration of new chemicals basically correspond to REACH Annex VIII ${ }^{5}$. Besides, also comparable to the REACH chemical safety report, it is necessary to provide information about physical-chemical properties, study results on toxicity and ecotoxicity, the assessment of persistence and bioaccumulation potential as well as the risk assessment considering exposure.

The old chemical legislation, developed by the Russian Federation, has been terminated and replaced by the new legislation.

\section{Set-up of a Chemical Substances Inventory}

For the formation of a chemical substances inventory in the Russian Federation (CIS), a timed action plan was implemented. The aim is to prepare the industry for the entry into force of several technical regulations of the EAEU 'On the Safety of Chemical Products'. The Technical Regulation TR EAEU 041/2017 was introduced referring to the inventory compilation under the Technical Regulation on Safe-

5 See, <https://echa.europa.eu/regulations/reach/registration/ information-requirements $>$ accessed 15 May 2020. 


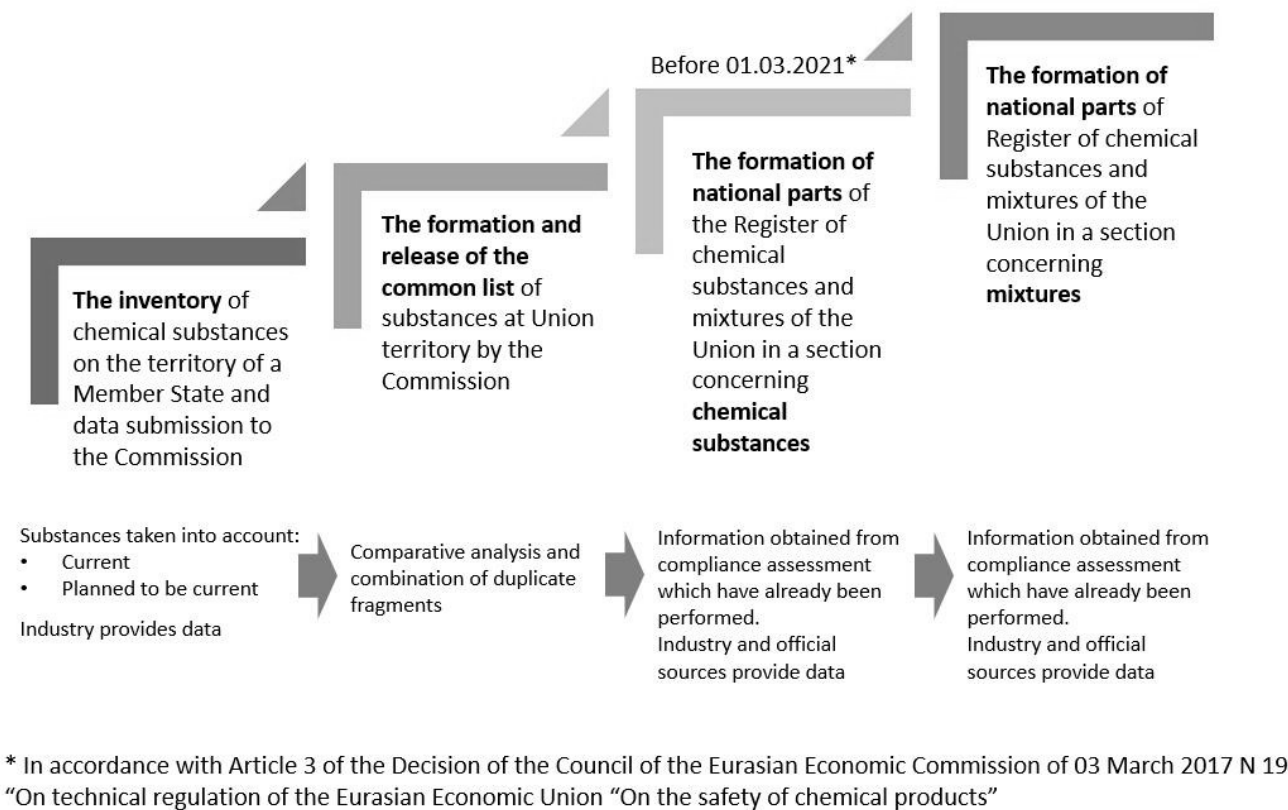

Figure 2: Action plan for Inventory Set-Up in EAEU (Source: CIS Coordination Center)

ty of Chemicals Products - also known as 'Eurasia REACH'. The new law consists of 14 chapters and seven annexes. Its purpose is to set out mandatory requirements for chemicals placed on the Eurasian market to ensure their safe use.

The inventory is the first step in the creation of a register/inventory of chemical substances and mixtures of the EAEU. The action plan was approved on 29 January 2019 and adopted by Russian Federation on 16 March 2019.

All chemical substances as such or within a mixture manufactured or imported, a company is placing or is planning to place on the Russian (or EAEU) market, are subject of the inventory listing. For chemical products manufactured or imported for the EAEU market as a chemical substance as such, the main component and all impurities and supplements present in a concentration of more than $0.1 \%$ (by weight) should be considered. For mixtures, it is necessary to take into account all components existing in a concentration of more than $0.1 \%$ (by weight).

Substances excluded from the inventory submission process are listed in Annex 1 of TR EAEU

6 Technical regulation of the Eurasian Economic Union 'On the safety of chemical products'.
$041 / 2017^{6}$ (substances for which the technical regulation does not apply). The following chemicals are excluded:

- chemical products intended for use in scientific research and development and/or obtained as a result thereof;

- minerals in their natural state of occurrence, as well as the following products, if not chemically changed: minerals, ores, ore concentrates, cement clinker, natural gas, liquefied gas, gas condensate, process gas and its components, dehydrated, desalted and stabilized oil, associated petroleum gas, coal, coke;

- medical products and preparations for veterinary use;

- perfumes and cosmetics;

- chemical products serving as a source of ionizing radiation (including wastes of such products), due to the presence of radiation;

- food products, including biologically active supplements and food additives, as well as finished animal feed;

- products in articles which during treatment in the customs territory of the EAEU do not change their chemical composition and which are not subject to decomposition or oxidation processes, and which do not form dusts, vapours and aerosols 
containing chemicals that are hazardous to the life and health of humans, animals or plants, the environment, or property;

- wastes from the production and consumption of chemical products, if they are to be recycled;

- chemical products that are subject to the procedure of customs transit through the territory of the EAEU.

\section{Industry Participation in the Inventory Procedure}

The chemical substances inventory reporting is a voluntary procedure in which a company has the right to submit data on chemical substances for inclusion in the inventory list, thereby declaring them as existing in the customs territory of the Union. The inventory list will be the basis for the formation of the Register of chemical substances and mixtures of the EAEU.

After the entry into force of TR EAEU 041/2017, all chemical substances that are not in the inventory will be considered 'new' for the customs territory of the Union. Before any chemical product containing such new substances can be placed on the EAEU marked, the respective company must undergo a registration procedure for these new substances. The registration requires the submission of a comprehensive dossier including the hazardous properties and analysis of risks to human health and the environment by submitting a chemical safety report. At the inventory stage - in contrary-the legislation requests only minimum information on the chemical substances, somewhat comparable to the EU REACH pre-registration process. The submission of information to the inventory as well as the reporting procedure is free of charge and does not require any documented proof that the substances to be notified were already placed on the marked of the Russian Federation (eg customs documentation, invoices, etc.).

Companies that for some reason did not participate in the inventory submission and have realized that their substances are not included in the inventory after the entry into force (and therefore are identified as new chemicals), can submit data to the Register before 2 June 2023 without conducting a registration procedure. However, in these cases proof and documentation needs to be provided that confirms the circulation of a chemical substance on the Union market before the effective date of TR EAEU 041/2017. Confirming documents may include a supply agreement, purchase and sale documentation, consignment notes, information on the presence of a chemical substance in the national lists of chemicals of an EAEU Member State, etc. After the entry into force of the legislation and the deadline of 2 June 2023, all 'new' chemicals need to be notified, even as part of the mixture.

\section{Data Submission Process}

In Russia, data may be submitted only by a Russian legal entity. However, a foreign company that does not have a legal entity in the Russian Federation, can appoint by mutual agreement a Russian representative for data submission. There are no special requirements to the representative like sufficient knowledge in the practical handling of the substances as it is defined for the Only Representative in the REACH Regulation. The Russian importer or customer can act as representative for inventory data submission, as well as a third-party representative (eg service provider).

To submit information on chemical substances at the inventory stage, it is necessary to complete a template and submit it electronically to the Ministry of Industry \& Trade of the Russian Federation ${ }^{7}$.

The submitter, which must be a Russian legal entity or more precisely, a company located in the EAEU, needs to send an information letter on official company letterhead, signed by the Managing Director with contact details of the responsible person in the company for the submission procedure. The subject of the letter should clearly identify the 'Inventory of Chemicals' and needs to be send to the Ministry of Industry \& Trade of the Russian Federation at the following address: Moscow, Presnenskaya Naberezhnaya, 10, bld. 2 (Tower 2 ).

The preliminary start date for accepting completed templates from industry was on 10 August 2019. The deadline for submitting substances to the inventory was initially set to 1 January 2020, but this was subject to change. In a statement by Russian Min-

7 See, <http://government.ru/en/department/54/events/> accessed 15 May 2020. 


\section{Comparison of Data/Information Requirements}

\begin{tabular}{|lll|}
\hline \multicolumn{1}{|c|}{ Inventory Submission } & \multicolumn{1}{c|}{ New Substance Notification } \\
\hline & 1. Substance Identification and Use Information \\
1. Substance Identification and Use & 2. Producer/importer information \\
Information & 3. Substance Identification Analysis (Spectra and \\
2. Classification & - Chromatogramms) \\
3. Producer/importer Information & 5. Chemical Safety Report: \\
& - Data on production \\
& - Hazard classification \& labelling \\
& - Recommendations on the safet use \\
& - Physical \& chemical properties \\
& - Effects on human health (acute \& chronic) \\
& - Environmental effects (acute \& chronic) \\
& - Impact risk assessment. \\
Cost estimate is $\mathbf{2 5 0 . 0 0 0 ~ \$ ~ p e r ~ N o t i f i c a t i o n ~ a n d ~ w i l l ~ t a k e ~ c a . ~} \mathbf{2}$ years & \\
\end{tabular}

Figure 3: Data requirements and differences of inventory notification versus new substance registration.

istry of Industry and Trade of 17 February 2020, the deadline was officially extended to 1 May 2020 and due to Covid-19 again officially extended o the 1st of August 2020.

For the inventory reporting all information about the chemical substances is requested without reference to the final product/mixture and the percentage in the composition, ie the notifiers need to provide a list of all the chemical substances in a single list. In addition, they do not need to duplicate the information, if several mixtures contain the same substance.

It is important to note, that the presence of a substance in the existing list of chemical substances does not necessarily exclude the need to submit data (or to complete the required information in the template) at the inventory stage, since the basis for the inventory of chemical substances and mixtures of the EAEU will be formed according to data provided by industry.

Regarding polymers, it is necessary at the inventory stage to provide information on monomers, as well as on all additive components in accordance with

8 See, <https://echa.europa.eu/support/substance-identification/ what-is-a-substance> accessed 15 May 2020. the formulation (for example, plasticizers, polymerization activators, etc.) in an amount of more than $0.1 \%$. Due to the high variety of polymers, notification of those is not applicable but information about polymers can be submitted to the inventory on an optional basis.

If the notifier produces a complex and variable composition substance (known as UVCB substance $\left.{ }^{8}\right)$, which consists of many components which cannot be determined explicitly, it is not required to fill out the inventory template for this UVCB substance as a whole or for each of the components in the composition. Instead, it is advised to determine and identify the UVCB substance by the production technology, used raw materials, typical content of components and definitive physicochemical parameters. Thus, it is requested to include information on a UVCB substance as a whole (without separation into components) with an indication of the CAS number assigned to it, if available.

The inventory submission template requires information like IUPAC name, molecular and structural formula, CAS, EC-No, synonyms, intended uses, volumes, furthermore information on customs codes, classification and submitter information should be provided. 
The harmonized system codes (HS-Codes) ${ }^{9}$ used for customs clearance should be included in the template as well. If HS codes are not applicable or available, this should be indicated in the template as 'Not applicable'. Russian names of chemicals can be included in the 'synonyms' column field.

Abbreviations (eg PVC for Polyvinyl Chloride) shall be entered in the 'Abbreviation' field.

The 'Applications' field should be completed by declaring the scope of use and purpose of the substance.

With regard to the 'Volume' field, for chemical substances contained in mixtures the annual production or import tonnage does not need to be indicated (no need to be counted individually) but instead the following phrase should be added: 'As part of a mixture' or 'As part of a polymer' for monomers. For chemical substances put on the EAEU market as such, the submitter needs to indicate the average production or import volume for the last three years. For substances where the volume will increase in the future (eg expansion of production capacity or increasing demand), the foreseen amount can be reported.

The column on 'Classification' shall be completed on a substance base, in the case of mixtures, for each component of a mixture separately. One line of the template should correspond to one chemical substance. If a substance is a part of several mixtures, the classification information should be submitted only once. If no data on hazard classification of a substance is available, the 'No data available' entry needs to be selected. For data on hazard classification of substances, all available data for each substance needs to be collected including information from open sources. The hazard classification criteria are established by the Standard GOST 32419-2013 which implements the Globally Harmonized System of Classification and Labelling of Chemicals (GHS).

In case no information can be provided, the terms 'No data available' or 'Not applicable' should be selected in order to complete the template.

To ensure confidentiality, the information on production or import volumes and the applicant's identity will not be made publicly available. The compiled inventory list of chemical substances on the EAEU territory will be anonymized, compositions of mixtures do not need to be submitted.

The submission template is password-protected to preserve the uniform settings for further automatic processing of the submitted data. To solve any arising problems with the template, a detailed descrip- tion and a screenshot of the error should be reported.

In addition, because the template was compiled for a Russian user, problems may arise on software running on non-Russified operating systems. Unfortunately, at the moment, this issue can be resolved only through the use of Russified software.

The Eurasian Economic Commission, the executive arm of the EAEU, will eventually merge all data collected from member states into one common inventory for the entire region.

\section{Conclusion}

The global trend of tightening chemical regulations is also continuing in Russia and the EAEU. The new chemical legislation of the EAEU, commonly known as 'Eurasia $R E A C H$ ', has taken over important elements from EU REACH, in particular regarding classification and labelling, safety data sheets and hazard, exposure and risk assessments. Hence, it is expected that this regulation will significantly improve the handling of hazardous substances in the EAEU.

A new chemical inventory is currently being compiled in Russia. If a substance is successfully notified to this Russian inventory, it should be included to a consolidated EAEU inventory at a later stage. In case a substance is not on the consolidated EAEU inventory, it may still be possible to include it until 2023, if documented proof can be provided that the substance was already on the EAEU market in the past.

Information on polymers can be submitted optionally as they are excluded from the notification process. In this regard it is important to note, that a regulatory definition of a polymer is not yet available. Thus, as a precautionary measure it might be advisable to submit polymers to the inventory in parallel to their monomers.

Finally, new substance registrations in EAEU are expected to be similar to EU REACH registrations, most likely including joint registration and Only Representative concepts. An advantage for companies in the chemical industry will be that safety studies that have already been carried out for existing chemical control legislations such as EU REACH can be used again for registration purposes in the EAEU. In turn,

9 See, <https://www.tariffnumber.com/> accessed 15 May 2020 
it goes without saying that agreements on global data sharing are getting increasingly important.

On the other hand, it is expected that small and medium-sized enterprises are going to face major challenges in the future business with Russia and the EAEU due to the language barrier (eg submission of registrations and inventory notifications in Cyrillic) and will require extensive support from local experts. 